\title{
Determinants of suboptimal breastfeeding practice in Debre Berhan town, Ethiopia: a cross sectional study
}

Teklemariam Gultie $^{1^{*}}$ (D) and Girum Sebsibie ${ }^{2}$

\begin{abstract}
Background: Optimal breastfeeding is inextricably linked to the achievement of M i ennium, Development Goals (MDGs) of eradicating extreme poverty and hunger, reducing child mortality ano (imp oving phaternal health. Breastfeeding is safe, promotes sensory and cognitive development and contrins antibo i:es that protect infants from common childhood illnesses. The objective of this study was to asse - suk optimal breastfeeding and its determinants factors among mothers who have children below 23 months o in Lebre Berhan, Ethiopia.

Methods: A community based cross sectional study was conducted nn 1 Mat/h 2015 until 30 March 2015. Five hundred forty eight mothers were included in the study using a ivo stage sampling technique. The data was collected by trained data collectors through pretested semi structured cuestionnaire. The collected data were cleaned, coded, entered and then analyzed using SPSS verson ? windows program. Descriptive statistics, binary and multivariable regression analysis with $95 \%$ confiden o interv. was carried out and $p$ value less than 0.05 used to determine the significant association. Late initiation of bi astffeding was defined as initiation of breastfeeding after one hour of delivery while early cessation of reac, fieedir $y$ was to stop breastfeeding before 24 months of age. According to World Health Organization zxclusi brezstfeeding was defined as the practice of feeding breast milk only, including expressed breast milk, to fants an, excluding water, other liquids, breast milk substitutes, and solid foods. Vitamin drops, minerals, oral phydra g solution (ORS) and medicines may be given.
\end{abstract}

Results: The prevalence of late initiat on of breastfeeding, not exclusively breastfeeding and early cessation of breastfeeding were $17.5 \%$ (95 \% Con dence linterval [CI] 15.2\%, 19.4), $49.8 \%$ (95 \% Cl 46.3, 50.5) and $12.8 \%$ (95\% Cl 11.7, 14.1) respectively. Birth thome n.... significantly associated with late initiation of breastfeeding (Adjusted Odds Ratio [AOR] 3.0; $95 \% \mathrm{Cl}$ 1.5, 6. \% - ' advice during antenatal care was a predictor of not exclusively breastfeeding (AOR1.7; $95 \% \mathrm{Cl} 1.2,2.5$ ) Reing r'iterate (AOR 3.2; $95 \% \mathrm{Cl} 1.2,8.3$ ) and no advice during antenatal care about breastfeeding (AOR 1 1:95\% Cl 1) \%. 3.4) were significantly associated with early cessation of breastfeeding.

Conclusion: Educationa, tatus, age, antenatal and postnatal follow up, resident and place of delivery were predictors of sia timal bi ástfeeding. Integrated and targeted interventions were recommended to achieve a better outcoime in $m$, amizing the late initiation, non-exclusive and early cessation of breastfeeding.

Keyworu B Breastfeeding, Debre Berhan, Community based, Determinants, Weaning

\footnotetext{
*Correspondence: tekledb2002@gmail.com

${ }^{1}$ Department of Midwifery, College of Medicine and Health Science, Arba

Minch University, Arba Minch, Ethiopia

Full list of author information is available at the end of the article
} 


\section{Background}

Globally, over one million newborn infants could be saved each year by initiating breastfeeding within the first hour of life [1]. In developing countries alone, early initiation of breastfeeding could save as many as 1.45 million lives each year by reducing deaths mainly due to diarrheal diseases and lower respiratory tract infections in children $[2,3]$.

Under-five deaths are increasingly concentrated in Sub-Saharan Africa and Southern Asia, while the share in the rest of the world dropped from $31 \%$ in 1990 to $17 \%$ in 2011. This clearly shows that over half of the MDG countries, including the above two are not on track to meet this target $[4,5]$. To achieve the fourth MDG, infant breastfeeding has been identified as one of the major intervention areas both globally and nationally [6].

The World Health Organization (WHO) recommend optimal breastfeeding; that newborns should have early initiation of breastfeeding within one hour after birth (timely initiation of breastfeeding), exclusive breastfeeding (defined as no water, other fluids or foods with the exception of drops or syrups consisting of vitamins, minerals supplements, or medicines for six months) and continued breastfeeding for two years or beyond with the addition of timely, adequate, safe and properly fed complementary foods [7]. Also, breastfeeding should be on deman', as often as the child wants day and night; and bottles nac; fiers should be avoided $[8,9]$.

Currently, the global rate of exclusive 1 r r tfeedin under six months of old is $37 \%$ [10]. Or third $f$ children under six months of age in de reloping countries are exclusively breastfed and only $39 \%$ of nevvborns in the developing world are put to the b. not within one hour of birth $[10,11]$. In develo Hry $_{y}$ ountries, the lack of exclusive breastfeeding for six ionths and absence of breastfeeding for infan ${ }^{+}, 6,23 m$ nths increased diarrheal disease and sso racu orbidity and mortality which is the secor. leading ause of death for under five children $[12,13$,

In Africa Asia, and 1 , cin America and the Caribbean 47-57\% o. infants vounger than two months are exclusively -astfe Fro children aged 6-11 months, $6 \%$ in Afr $\Rightarrow$ as d $10 \%$ in Asia have stopped breastfeeding, as have \% In Latin America and the Caribbean $[9,14]$. The prev rence of EBF among women in Kigoma Municipality was $58 \%$ [15].

In Ethiopia, breastfeeding is nearly universal (98\%). However only 51.5 and $52 \%$ of children started breastfeeding within an hour and EBF for six months respectively [16]. At 6-9 months only about half of children receive complementary foods. Overall, only four percent of children ages 6-23 months are fed appropriately. Initiation of breastfeeding within one hour after delivery was lowest in the Amhara and Somali regions (38 and
$40 \%$, respectively), and highest in the Southern and Dire Dawa regions (67 and $66 \%$, respectively) [16]. In Goba southeast Ethiopia, the prevalence of early initiation of breastfeeding before one hour of delivery and exclusive breastfeeding were 52.4 and $71.3 \%$, respectively [17] while in Dale district was 83.7 and $87.1 \%$ respectively [18].

The prevalence of suboptimal breastfeeding practices is high in developing countries [19]. Suboptimal breastfeeding practices may threaten infant health $\mathrm{n} d$ ass $)^{-1}$ ated with over a million deaths each year and $16 \%$ s the global disease burden in children [7]. 'uboptinal breastfeeding accounts for $45 \%$ of neonatal in. "ectisus deaths, $30 \%$ of diarrheal deaths and $8 \%$ of act.e respiratory deaths in under five childrer $(20,71]$. Promotion of EBF is the single most cost effer ive + +erverion to reduce infant mortality in developin, ountries.

A number of difieren $\downarrow$ factors in different countries were mentioner. a predi cors for suboptimal breastfeeding such as esi ance, family size, birth order, maternal age, number of 'ildren, nutritional status, encouragement, co ..-oling by hospital staff to initiate, hospital delivery, no ore st problem, maternal educational level, current marital status, child age, and economic status [1/, 2-26]. This study aimed to identify the determinants of suboptimal breastfeeding practice in Debre erh n town, Ethiopia.

\section{Methods}

\section{Study area and period}

The study was conducted in Debre Berhan town from 1 March 2015 until 30 March 2015. The town has nine administrative kebeles (the lowest government administrative unit in Ethiopia). In 2007 there were a total of 65,231 population, of whom 31,668 are men and 33,563 women of which 2,649 are infants [27]. The town has one health center and one referral hospital.

\section{Study design and sample size}

A community based cross-sectional study was conducted. The sample size was calculated using single population formula by the considering the $95 \%$ confidence interval, $5 \%$ desired precision, $34 \%$ prevalence of exclusive breastfeeding $(p=0.34)$, design effect 1.5 and $5 \%$ non-response rate the final sample size was 548 .

\section{Population}

The source populations were mothers having children aged less than 23 months old in Debre Berhan town and the study populations were those mothers who reside in the selected kebeles. Those mothers who were not a permanent resident of the town and seriously ill at the time of data collection were excluded from the study. 


\section{Sampling procedure}

A two stage sampling technique was used in sampling the study participants. From the total of nine kebeles, six kebeles were selected by simple random sampling technique. The total number of mothers who have children less than two years of age in those selected kebeles were 5,456. From these target population that the required sample size was taken according to proportional allocation to sample in each selected kebeles.

Finally, systematic random sampling technique was used to get the individual participant at household level. The center of each kebele was located and the first household identified using a spinning pen. After determining the sampling interval for each kebele the data was collected following to the right direction of the first selected household.

\section{Measurement}

\section{Suboptimal breastfeeding}

When the study participants didn't start breastfeeding within an hour of delivery, have started complementary food early before six months of life.

\section{Exclusive breastfeeding}

The practice of feeding breast milk only, including expressed breast milk, to infants and excluding water, other liquids, breast milk substitutes, and solid oods. Vitamin drops, minerals, oral rehydrating solution (C.'S) and medicines may be given.

\section{Late initiation of breastfeeding}

The initiation of breastfeeding after or hour of birth.

\section{Early cessation of breastfeeding}

The act of substituting other fooc for tne mother's milk in the diet of a child ea iy b fore si months.

\section{Data collection ar. analysis}

The structured que innaire was prepared in English and then translated to imharic. The questionnaire includes socr demographic characteristics of mothers and infant hasic for nation about breastfeeding and questio:- on matern ty experiences. Data was collected using a face $~ \%$ tace interview by trained Nurse Professionals. The qua cy of the data was maintained by using the standard questionnaire, training was given for data collectors and supervisors and the collected data were checked every day for its completeness. The collected data was entered using Epi-info window version 3.5.1 and exported to SPSS Windows version 20 for further analysis. Descriptive statistics and logistic regression analysis was carried out to describe the variables and to determine their relationship with the outcome variable. Variables were entered in binary logistics regression and those with $p$ value $<0.25$ were entered in to multivariable analysis. Odds ratio (OR) with $95 \%$ confidence interval $(\mathrm{CI})$ at $p<0.05$ was used to determine the significance level of association between predictors and outcome variable.

\section{Ethical considerations}

The study was approved by Institutional I viey Board of Addis Ababa University. North Shoa Hea 7 Bureau was informed about the objective of t'ke study th Jugh a support letter from Addis Ababa Iniv sity a d a written permission was obtained from Zonal. alth bureau to the respected study site in rder to get cooperation and participation. All of th stu naricipants were informed about the purr ose of $\mathrm{L}$. study and oral consent was obtained befor $1 \mathrm{l}$ erview. Respondents were informed that thev have the right to refuse or terminate the interview nd he information provided by each respondent was k 'cunciential.

\section{Results}

Socio-demo yraphic characteristics

Fiv hundred forty eight mothers were participated in the st dy with a response rate of $100 \%$. More than one hird (36\%) of mothers were in the age group of 25-29 ye.rs. Concerning the educational status of mothers, $43.4 \%$ had not attended any formal education and27\% of mothers had accomplished primary school. Half of the participants $(50.4 \%)$ had female infants and 306 $(55.9 \%)$ were in the age group of $0-11$ months. The mean age of infants was $10.8( \pm 7.4)$ months (Table 1$)$.

\section{Maternal health service utilization and obstetric related factors}

Majority (94.3\%) of the participants had antenatal care. Four hundred sixty one $(84.1 \%)$ delivered at a health institution and $336(61.3 \%)$ received information about breastfeeding. From those who received information about breastfeeding, (37.8 \%) and (38.9\%) were informed to initiate breastfeeding immediately and to practice exclusive breastfeeding for the first six months respectively. The majority $(87.2 \%)$ of the respondents in this study had spontaneous vaginal delivery (Table 2).

\section{Practice of breastfeeding initiation}

The result showed that, $98.2 \%$ of mothers practiced ever breastfeeding. Among them $82.5 \%$ initiated breastfeeding immediately and $17.5 \%$ after an hour of delivery. The perceived reasons for late initiation of breastfeeding were: Caesarean section delivery (47.4\%), maternal and baby illness $(23.2 \%)$, lack of information (17.9\%) and milk insufficiency (11.5\%) (Table 3). 
Table 1 Socio-demographic characteristics of the respondents in Debre Berhan town, $2015(n=548)$

\begin{tabular}{llll}
\hline Variables & Category & Number & Percent \\
\hline Age of mothers & $15-19$ & 36 & 6.6 \\
& $20-24$ & 128 & 23.4 \\
& $25-29$ & 201 & 36.7 \\
& $30-34$ & 129 & 23.5 \\
& $\geq 35$ & 54 & 9.9 \\
Educational status & Illiterate & 202 & 36.9 \\
& Able to read/write & 36 & 6.5 \\
& Primary (1-8) & 148 & 27 \\
Occupation & Secondary \& above & 162 & 29.6 \\
& Housewife & 402 & 73.4 \\
& Farmer & 12 & 2.2 \\
Sex of infant & Student & 4 & 0.7 \\
Age of infant in months & Male & 272 & 49.6 \\
& Female & 276 & 50.4 \\
& 6-11 & 161 & 29.4 \\
& $12-17$ & 145 & 26.5 \\
& $18-23$ & 118 & 21.5 \\
& & 124 & 22.6 \\
\hline
\end{tabular}

\section{Breastfeeding initiation and associated factors}

On binary logistic regression analysis place of resi 'snce, educational status, antenatal care, place of del very, $p r$ ity, mode of delivery and advice during and ath deliver

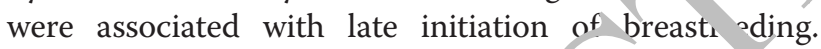
Rural dwellers were more likely to pra tice late initiation

Table 2 Reproductive health related history a $n n g$ women in Debre Berhan town, $2015(n=548)$

\begin{tabular}{|c|c|c|c|}
\hline Variables & Category & Number & Percent \\
\hline \multirow[t]{4}{*}{ Antenatal care } & is & 516 & 94.1 \\
\hline & & 32 & 5.9 \\
\hline & & 244 & 47.3 \\
\hline & No & 272 & 52.7 \\
\hline \multirow[t]{5}{*}{ Place of birth } & Home & 87 & 15.9 \\
\hline & Health institution & 461 & 84.1 \\
\hline & 1 & 192 & 35 \\
\hline & $2-4$ & 274 & 50 \\
\hline & $5+$ & 82 & 15 \\
\hline \multirow[t]{3}{*}{ Mode of delivery } & Spontaneous & 478 & 87.2 \\
\hline & Cesarean section & 66 & 12 \\
\hline & Instrumental & 4 & 0.7 \\
\hline \multirow[t]{2}{*}{ Advice during postnatal } & Yes & 303 & 55.3 \\
\hline & No & 245 & 44.7 \\
\hline \multirow[t]{2}{*}{ Information about breastfeeding } & Yes & 336 & 61.3 \\
\hline & No & 212 & 38.7 \\
\hline
\end{tabular}

Table 3 Breastfeeding initiation practice among women in Debre Berhan town, $2015(n=548)$

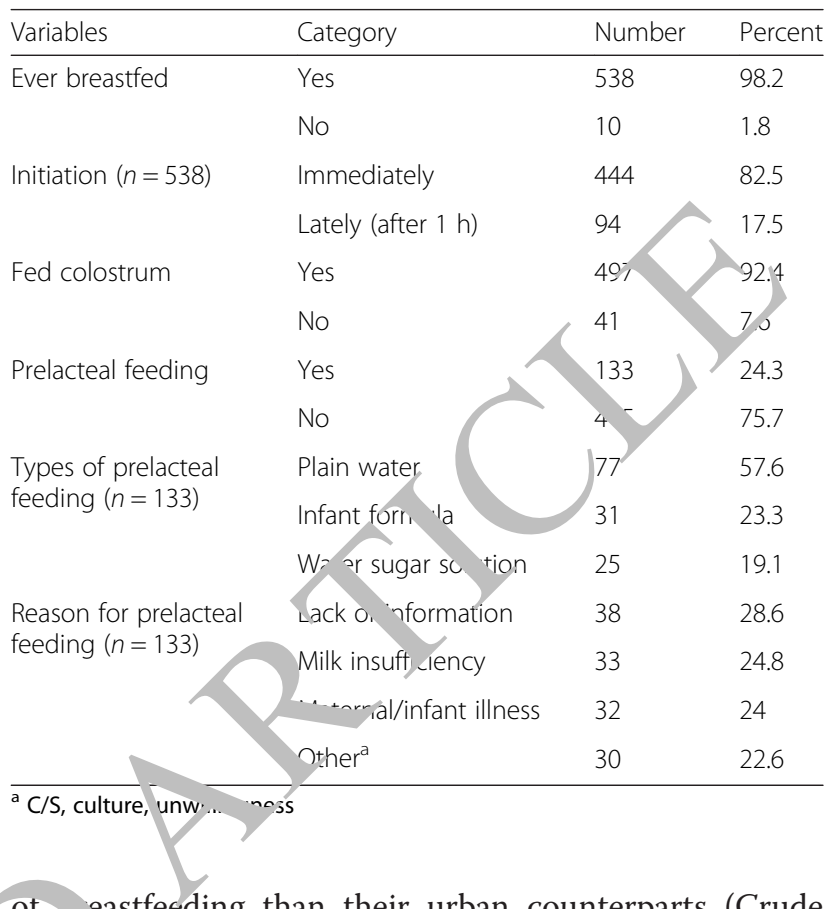
of eastfeeding than their urban counterparts (Crude Odds Ratio [COR] 5.3; $95 \%$ CI 3.3, 8.5). Similarly, otbers who were illiterate (COR 5.5; 95 \% CI 2.7, 11.0) and had no antenatal care (COR 5.1; $95 \%$ CI 2.4, 10.7) were more likely to initiate breastfeeding after the first hour of delivery than their counterparts. The odds of late initiation of breastfeeding were higher in home births than health institutional delivery (COR 7.2; $95 \%$ CI $4.3,12.0)$.

After multivariable analysis, home delivery (Adjusted Odds Ratio [AOR]3.0; 95 \% CI 1.5, 6.0) and no information about breastfeeding during postnatal care (AOR 2.0; $95 \%$ CI 1.1, 3.6) were the predictors of late initiation of breastfeeding (Table 4).

\section{Exclusive breastfeeding and associated factors}

Among socio-demographic, obstetrics and health service factors, not exclusively breastfeeding was associated with no antenatal care and lack of advice during antenatal care. In multivariable logistic regression only lack of advice on breastfeeding during antenatal care (AOR 1.7; $95 \%$ CI 1.2, 2.5) was associated with not exclusively breastfeeding (Table 5).

\section{Early cessation and associated factors}

On binary logistic regression analysis, illiteracy, no antenatal care and para one were significantly associated with early cessation of breastfeeding. During multivariable analyses, mothers in the age group 15-19 years (AOR 0.1; $95 \%$ CI 0.01, 0.85) were less likely to have early cessation; mothers who didn't receive advice about 
Table 4 Initiation of breastfeeding and associated factors among women in Debre Berhan town, $2015(n=548)$

\begin{tabular}{|c|c|c|c|c|c|}
\hline \multirow[t]{2}{*}{ Variables } & \multirow[t]{2}{*}{ Category } & \multicolumn{2}{|c|}{ Initiation of breastfeeding } & \multirow[t]{2}{*}{ COR $(95 \% \mathrm{Cl})$} & \multirow[t]{2}{*}{ AOR $(95 \% \mathrm{Cl})$} \\
\hline & & Immediately & Late & & \\
\hline \multirow[t]{4}{*}{ Educational status } & Illiterate & $144(71.3)$ & $58(28.7)$ & $5.5(2.7,11)^{*}$ & $1.4(0.6,3.2)$ \\
\hline & Able to read/write & $28(77.8)$ & $8(22.2)$ & $4.1(1.5,11.2]$ & $2.3(1,8.5)^{*}$ \\
\hline & Primary (1-8) & $130(87.8)$ & $18(12.2)$ & $1.7(0.8,3.8)$ & $0.98(0.42,2.3)$ \\
\hline & Secondary \& above & $147(91)$ & $15(9)$ & 1.0 & \\
\hline \multirow[t]{3}{*}{ Parity } & 1 & $158(82.3)$ & $34(17.7)$ & 1.0 & \\
\hline & $2-4$ & $230(83.95)$ & $44(16.05)$ & $1.0(0.6,1.7)$ & \\
\hline & $5+$ & $56(68.3)$ & $26(31.7)$ & 2.5 & \\
\hline \multirow[t]{2}{*}{ Antenatal care } & Yes & $428(82.95)$ & $88(17.05)$ & 1.0 & \\
\hline & No & $16(51.6)$ & $15(48.4)$ & $4,10.7)$ & $2.4(0.7,5.8)$ \\
\hline \multirow[t]{2}{*}{ Advice during antenatal care about breastfeeding } & Yes & $219(91.2)$ & 2 & & 1.0 \\
\hline & No & $225(75.5)$ & & $0,5.7)$ & $2.4(1.2,4.5)^{*}$ \\
\hline \multirow[t]{2}{*}{ Place of delivery } & Home & $45(51.7)$ & & $4.3,12)^{*}$ & $3.0(1.5,6.0)^{*}$ \\
\hline & Health institution & $399(86.6)$ & & 1.0 & 1.0 \\
\hline \multirow[t]{2}{*}{ Advice during postnatal care about breastfeeding } & Yes & $272(89.8)$ & & 1.0 & 1.0 \\
\hline & No & $172(72$ & $6,28)$ & $0.3(0.16,0.4)$ & $2.0(1.1,3.6)^{*}$ \\
\hline \multirow[t]{2}{*}{ Mode of delivery } & SVD & $394(82$ & 7.5) & $1.7(0.9,3.2)$ & \\
\hline & $\mathrm{C} / \mathrm{S}$ and instrumental & $50(71.5)$ & $20(28.5)$ & 1.0 & \\
\hline
\end{tabular}

breastfeeding (AOR 1.9; 95 \% CI 1.0, 3.4) were more likely to cease breastfeeding early (Table 6).

\section{Discussion}

The current study attempted to determins the pre lence and associated factors of suboptimal oreastfeeding (late initiation, not exclusively breastfeeding nd early cessation of breastfeeding).

Majority $(98.2 \%)$ of the stucy tricipant practiced breastfeeding. This finding is sin ar with the national reas feeding prevalence (96\%) and with $98 \%$ breastfer ding in Oromia region, $96.5 \%$ in Amhara region and $99.1 \%$ in Dire Dawa [16].

The prevalence of late initiation of breastfeeding was $17.5 \%$; (95 \% CI 14.2 \%, $19.7 \%$ ). This finding is consistent with the Dale district Southern region, where the prevalence of late initiation of breastfeeding was $16.3 \%$. However, this finding is less than the study conducted in Goba district Ethiopia where majority (47.8\%) of infants initiate breastfeeding after an hour of delivery [17]. These

Table 5 Exclusive brearffees $n g$ win the age of six months and associated factors among women in Debre Berhan town, 2015

\begin{tabular}{|c|c|c|c|c|c|}
\hline \multirow[t]{2}{*}{ Variables } & \multirow[t]{2}{*}{ Category } & \multicolumn{2}{|c|}{ Exclusive breastfeeding } & \multirow[t]{2}{*}{$\operatorname{COR}(95 \% \mathrm{Cl})$} & \multirow[t]{2}{*}{ AOR $(95 \% \mathrm{Cl})$} \\
\hline & & No & Yes & & \\
\hline \multirow[t]{5}{*}{ Parity } & 1 & $103(53.6)$ & $89(46.4)$ & 1.0 & \\
\hline & $2-4$ & $129(47.1)$ & $145(52.9)$ & $0.77(0.5,1.1)$ & \\
\hline & $5+$ & $43(52.4)$ & $39(47.6)$ & $2.54(1.34,4.7)$ & \\
\hline & Yes & $253(49)$ & $263(51)$ & 1.0 & 1.0 \\
\hline & No & $21(67.7)$ & $10(32.3)$ & $2.2(1.0,4.7)^{*}$ & $1.7(0.8,3.7)$ \\
\hline \multirow[t]{2}{*}{ Advice during antenatal care about breastfeeding } & Yes & $102(41.8)$ & $142(58.2)$ & 1.0 & 1.0 \\
\hline & No & $173(56.9)$ & $131(43.1)$ & $1.8(1.3,2.6)^{*}$ & $1.7(1.2,2.5)^{*}$ \\
\hline \multirow[t]{2}{*}{ Place of delivery } & Home & $42(48.3)$ & $45(51.7)$ & $0.9(0.6,1.4)$ & \\
\hline & Health institution & $233(50.5)$ & $228(49.5)$ & 1.0 & \\
\hline \multirow[t]{2}{*}{ Advice during postnatal care about breastfeeding } & Yes & $146(48.2)$ & $157(51.8)$ & 1.0 & \\
\hline & No & $129(52.7)$ & $116(47.3)$ & $1.2(0.9,1.7)$ & \\
\hline
\end{tabular}


Table 6 Early cessation of breastfeeding and associated factors among women in Debre Berhan town, 2015 ( $n=548)$

\begin{tabular}{|c|c|c|c|c|c|}
\hline \multirow[t]{2}{*}{ Variables } & \multirow[t]{2}{*}{ Category } & \multicolumn{2}{|c|}{ Continuing to breastfeed } & \multirow[t]{2}{*}{ COR $(95 \% \mathrm{Cl})$} & \multirow[t]{2}{*}{ AOR $(95 \% \mathrm{Cl})$} \\
\hline & & No & Yes & & \\
\hline \multirow[t]{5}{*}{ Age of mothers } & $15-19$ & $1(2.8)$ & $35(97.2)$ & $0.1(0.01,0.8)^{*}$ & $0.1(0.01,0.85)^{*}$ \\
\hline & $20-24$ & $9(7)$ & $119(93)$ & $0.3(0.1,0.7)$ & $0.34(0.12 .1 .0)$ \\
\hline & $25-29$ & $24(11.9)$ & $177(88.1)$ & $0.5(0.2,1.0)$ & $0.6(0.3,1.5)$ \\
\hline & $30-34$ & 24 (18.6) & $105(81.4)$ & $0.8(0.4,1.7)$ & 1) \\
\hline & $\geq 35$ & $12(22.2)$ & $42(77.8)$ & 1.0 & \\
\hline \multirow[t]{4}{*}{ Educational status } & Illiterate & 39 (19.3) & $163(80.7)$ & $4.6(2.1,10.2)^{*}$ & $3.3)^{*}$ \\
\hline & Read/write & $10(27.8)$ & $26(72.2)$ & 7.4 & $4.9(1.5,15.7)$ \\
\hline & Primary (1-8) & $13(8.8)$ & $135(91.2)$ & 4.6) & $6,4.5)$ \\
\hline & Secondary \& above & $8(4.9)$ & $154(95.1)$ & & 1.0 \\
\hline \multirow[t]{3}{*}{ Parity } & 1 & $16(8.3)$ & $176(91.7)$ & & $1.3(0.5,3.2)$ \\
\hline & $2-4$ & $35(12.8)$ & & 0.9) & $1.0(0.5,2.0)$ \\
\hline & $5+$ & $19(23.2)$ & $63(76.8)$ & 1.0 & \\
\hline \multirow[t]{2}{*}{ Antenatal care } & Yes & $453(87.8)$ & & 1.0 & \\
\hline & No & $24(77.4)$ & & $2.1(0.9,50$ & \\
\hline \multirow[t]{2}{*}{ Advice during antenatal care about breastfeeding } & Yes & $19(7.8)$ & $225, ? .2)$ & 1.0 & 1.0 \\
\hline & No & $51(16.8)$ & & $2.4(1.4,4.2)^{*}$ & $1.9(1.0-3.4)^{*}$ \\
\hline \multirow[t]{2}{*}{ Place of delivery } & Home & $10(11.5)$ & $77(88.5)$ & $0.9(0.4,1.8)$ & \\
\hline & Health insti & & $401(87)$ & 1.0 & \\
\hline \multirow[t]{2}{*}{ Advice during postnatal care about breastfeeding } & Yes & .2) & $269(88.8)$ & 1.0 & \\
\hline & No & & $209(85.3)$ & $1.4(0.8,2.2)$ & \\
\hline
\end{tabular}

COR Crude Odds Ratio, Cl Confidence Interval, *significant at $p$ valu less an 0.05

variations could be due to the reason that te study rarticipants in Goba district having differen - cultural practices such as discarding the colostrum wi ch takes time to remove the colostrum and this may de. the timing of initiation.

The prevalence of late initiation of breastfeeding in this study was relatively simi ${ }^{1} \mathrm{rr} \mathrm{w}$ h stua ss done in Mauritania (19\%) and Eritrea (22\%). vis.... vely lower than the studies done in Harari 36 \%) an Dire Dawa (34\%). This may be due to the difere data collection time periods. However, it is ruch lower han the studies done in Sudan (45.8\%), л Ja (505\%), Ethiopia (national) (48\%), and Amhar region $(63.0 \%)$ where of mothers initiate breastfee' $n g$ a ter an Lour of birth, [1, 3, 27]. This might be due to the mall sample size of the current study whereas the other $\mathrm{em}_{\mathrm{t}}$ 'oyed large scale study.

The findings showed that place of delivery and advice on breastfeeding during antenatal visits and postnatal care were factors associated with late initiation of breastfeeding practices. In this study, rural mothers were more likely to initiate breastfeeding after an hour of delivery than urban mothers. This result is consistent with the finding from Goba districts where late initiation of breastfeeding was more common in rural areas than in the urban areas [17]. This finding is also consistent with national finding where breastfeeding initiation within one hour after birth was more common in urban areas than in rural areas, as with a study done in urban and rural areas of Vietnam [28]. The Ethiopian and Demographic and Health Survey result showed that the likelihood that a child is breastfed in the first hour after birth increases with the mother's educational status [16]. The current finding didn't indicate the effect of mother's educational status. This difference could be as a result of the study participants included in the current study were urban dwellers where access to education and health information is high whereas the Demographic survey included the large number of rural dwellers.

In this study, the prevalence of not exclusively breastfeeding was $49.8 \%$ (95\% CI 46.3, 51.6) which is almost similar with the national prevalence of exclusive breastfeeding (52 \%), with Tanzania (42 \%) and Malaysia $(45.8 \%)[15,16,29]$. The finding is higher than the finding from Goba districts (28.9\%) and Dale districts (12.9\%) Ethiopia [17, 18]. This difference might be related to the current advocating of exclusive breastfeeding by the health care providers and media.

Not exclusively breastfeeding was associated with lack of advice during antenatal care. Mothers who didn't receive advice about breastfeeding practice not exclusively 
breastfeeding when compared with mothers who got an advice. This finding is in contrast with the study result in Lebanon where EBF is significantly associated with maternal education [23]. This might be due to the reason that currently in Ethiopia intensive heath education is provided about breastfeeding at the time of antenatal care visit for the mothers according to the focused antenatal care guideline.

Different factors such as maternal age, educational status and advice during antenatal care were predictor of early cessation of breastfeeding. Younger age mothers practice early cessation than their counterparts. This might be as a result of younger women engaging in different activities such as education and employment, which makes difficult for exclusive feeding.

However, this study has some limitations such as recall bias and suboptimal breastfeeding was assessed through self-reporting questions, and this study utilized cross sectional study design which made it impossible to establish a causal relationship between the outcome and exposure variables.

\section{Conclusion}

The study showed that the prevalence of late initiation of breastfeeding was low. Mothers tend to introduce prelacteal foods due to some perceived and traditional practices such as culture, breast milk insufficiency ar.d being birth via Caesarean section. Predictors $c$ late in. ation of breastfeeding were: being illiterate, 1 om telivery, lack of antenatal care, receiving no antencitai and po 'natal advice on breastfeeding. The prevalenc of not exclusively breastfeeding was $49.8 \%$.

The early cessation practice of mothu is relatively good as compared to that of no ex - ively breastfeeding and similar with the lnte initi tion of breastfeeding. At the time of the sur ey, $2.8 \%$ infants are weaned from breastfeeding and $t_{1}$ preurctors for early cessation were maternal ac,e, educatio, il status and advice during antenatal care

Optimal breartfeeding is important for the wellbeing of infants es, cially in developing countries like Ethiopia wher arrhe, r.sease and pneumonia are prevalent. Con nur "1s advocating of exclusive breastfeeding and early initiatic of breastfeeding by the health care providers and through afferent media is important. Health education should be provided to enable the mother to accept behavioral changes towards timely initiation, exclusive breastfeeding and timely weaning of breastfeeding.

\section{Competing interests}

The authors declare that they have no competing interests.

\section{Authors' contribution}

GS and TG conceived the study and undertook statistical analysis. GS and TG supervised the study and made the study design. GS and TG contributed to the writing of the manuscript and both authors approved the submitted version of the manuscript.

\section{Acknowledgement}

The authors thank all the study participants and Shirley Strong a lecturer in Queens Belfast for her language editing service.

\section{Author details}

${ }^{1}$ Department of Midwifery, College of Medicine and Health Scie'sce, Arba Minch University, Arba Minch, Ethiopia. ${ }^{2}$ Department of Nursing and Midwifery, College of Health Science, Addis Ababa Universit, Add; Ababa, Ethiopia.

Received: 8 September 2015 Accepted: 14 March 716 Published online: 22 March 2016

\section{References}

1. Edmond KM, Zandoh C, Quigley/. Delc d breacteeding initiation increases risk of neonatal mor Mlity. P. Jiatrics. 2006;117:380-6.

2. Walker C, Rudan I, Liu L, N- H, Theodo, ou, E. Global burden of childhood pneumonia and diarrhe ta. La ret. 2013;3\& 1:1405-16.

3. UNICEF. Childinfo: Monitoring th Situation of Children and Women. 2009 http://data.unicef.ry. Accessed 18, eb 2015.

4. Hill K, You D, I M M Jestergaard MZ. Child mortality estimation: accelerated progi in reuning global child mortality, 1990-2010. PLOS Med. 2012:9:e100130.

5. You D, va "rin T, Sala na P, Jones G. Levels and trends in under-5 mortality, $190 \mathrm{j}-\mathrm{z}$. Lancet. 2010;376(97405):931-3.

6. Bryce J, el trifeen S, Pariyo G, Lanata CF, Gwatkin D. Reducing child mortality: c n public health deliver? The Lancet. 2003;362:159-64. rld Health Organization. Guiding Principles for Complementary Feeding of le Breastfed Child. Division of Health Promotion and Protection. 2004. Wc Id Health Organization. Maternal, Newborn, Child and Adolescent H.ealth. 2013. http://www.who.int/maternal_child_adolescent/about/ structure/en/. Accessed 22 Feb 2015.

Tawiah C. Early initiation of breast-feeding in Ghana: barriers and facilitators. J Perinatol. 2008;28(2):46-52

10. World Health Organization. World Breastfeeding Week 1-7 August. Understanding the past-Planning the Future: Celebrating 10 Years of WHO/ UNICEF's Global Strategy for Infant and young child feeding. 2012.

11. Begum K, Dewey KG. Impact of early initiation of exclusive breastfeeding on newborn deaths. 2010. http://www.popline.org/node/562148. Accessed 20 Feb 2015. http://www.who.int/maternal_child_adolescent/news_events/ news/2012/30_07_2012/en/. Accessed 23 Feb 2015.

12. Alexander R. Does shortening the training on integrated management of childhood illness guidelines reduce effectiveness? 2008. http://www.who. int/maternal_child_adolescent/documents/9789241597210/en/. Accessed 21 Feb 2015.

13. Imdad A, Yakoob MY, Bhutta ZA. Effect of breastfeeding promotion interventions on breastfeeding rates, with special focus on developing countries. BMC Public Health. 2011;11:3.

14. World Bank. Repositioning nutrition as central to development: a strategy for large scale action. 2006. http://documents.worldbank.org/curated/en/ 2006/01/6991063. Accessed 20 Feb 2015.

15. Nkala TE, Msuya SE. Prevalence and predictors of exclusive breastfeeding among women in Kigoma region, Western Tanzania: a community based cross-sectional study. Int Breastfeed J. 2011;6:17.

16. Ethiopian central statistics agency. Ethiopia Demographic and Health Survey 2000. 2001. http://www.etharc.org/index.php/resources/download/view. download/\%E2\%80\%A6/682. Accessed 20 Feb 2015.

17. Setegn T, Gerbaba M, Belachew T. Determinants of timely initiation of breastfeeding among mothers in Goba Woreda, South East Ethiopia: A cross sectional study. BMC Public Health. 2011;11:217.

18. Alemayehu M, Abreha K, Yebyo H, Zemichael K. Factors associated with timely initiation and exclusive breastfeeding among mothers of Axum town, Northern Ethiopia. Sci J Ppublic Health. 2014;2:394-401.

19. Kimani EW. Patterns and determinants of breastfeeding and complementary feeding practices in urban informal settlements, Nairobi Kenya. BMC Public Health. 2011;26:11.

20. World Health Organization, UNICEF. Global Strategy for Infant and Young Child Feeding. 2003. 
21. Du Plessis D. Breastfeeding: Mothers and health practitioners in the context of private medical care in Gauteng. Health SA Gesondheid. 2009;14:1.

22. Alemayehu T, Haidar J, Habte D. Determinants of exclusive breastfeeding practices in Ethiopia. Ethiop J Health Dev. 2009;23:1.

23. Batal M, Boulghourjian C, Abdallah A. Breast-feeding and feeding practices of infants in a developing country: a national survey in Lebanon. Public health Nutr. 2006;9:3.

24. Ogunlesi TA. Maternal socio-demographic factors influencing the initiation and exclusivity of breastfeeding in a Nigerian semi-urban setting. Matern Child Health J. 2010;14:3.

25. Qiu L, Zhao Y, Binns CW, Lee AH, Xie X. A cohort study of infant feeding practices in city, suburban and rural areas in Zhejiang Province, PR China. Int Breastfeed J. 2008;3:3

26. Veghari $G$, Mansourian A, Abdollahi A. Breastfeeding status and some related factors in northern Iran. Oman Med J. 2011;26:342.

27. Commission Population counsel. Summary and Statistical Report of the 2007 Population and Housing Census. Federal Democratic Republic of Ethiopia. 2008. http://www.csa.gov.et/index.php/2013-02-20-14-51-51/201304-01-11-53-00/census-2007. Accessed 18 Feb 2015.

28. Thu HN, Eriksson B, Khanh TT, Petzold M. Breastfeeding practices in urban and rural Vietnam. BMC Public Health. 2012;12:964.

29. Tan KL. Factors associated with not exclusively breastfeeding among 4week post-partum mothers in Klang district, Peninsular Malaysia. Malays J Nutr. 2009:15:11.

\section{Submit your next manuscript to BioMed Central} and we will help you at every step:

- We accept pre-submission inquiries

- Our selector tool helps you to find the most relevant journal

- We provide round the clock customer support

- Convenient online submission

- Thorough peer review

- Inclusion in PubMed and all major indexing services

- Maximum visibility for your research

Submit your manuscript at www.biomedcentral.com/submit 